\title{
Reversed impacts by specialist parasitoids and generalist predators may explain a phase lag in moth cycles: a novel hypothesis and preliminary field tests
}

\author{
Netta Klemola*, Annette Heisswolf, Tea Ammunét, Kai Ruohomäki \& \\ Tero Klemola
}

Section of Ecology, Department of Biology, Fl-20014 University of Turku, Finland (*corresponding author's e-mail: netta.klemola@utu.fi)

Received 5 Nov. 2008, revised version received 25 June 2009, accepted 26 May 2009

Klemola, N., Heisswolf, A., Ammunét, T., Ruohomäki, K. \& Klemola, T. 2009: Reversed impacts by specialist parasitoids and generalist predators may explain a phase lag in moth cycles: a novel hypothesis and preliminary field tests. - Ann. Zool. Fennici 46: 380-393.

\begin{abstract}
Among cyclic populations of herbivores, inter-specific temporal synchrony has been attributed to both climatic factors and trophic interactions. In northern Europe, winter and autumnal moths undergo regular 9-11 year population cycles. The winter moth cycle has typically been phase-locked with that of the autumnal moth, but with a 1-3year phase lag. We examined potential effects of natural enemies on this phase lag using field experiments and observational data. We found that larval parasitism was significantly higher in autumnal than in winter moths. Conversely, pupal predation by generalist invertebrates was clearly greater in winter than in autumnal moths. The difference in parasitism rates may contribute to the earlier collapse of the autumnal moth cycle. In addition, the phase lag may be strengthened by higher pupal mortality in winter moths in the early increase phase of the cycles. As a consequence, we put forward a hypothesis on reversed effects of natural enemies, providing a potential explanation for phase-lagged population cycles of these moth species.
\end{abstract}

\section{Introduction}

High-amplitude density fluctuations showing a regular periodicity is a well known phenomenon in many forest lepidopterans (Myers 1988). Population cycles among and within lepidopteran species tend to be synchronous over large geographic areas, at least within a time window of a few years (Williams \& Liebhold 1995, Myers 1998, Peltonen et al. 2002, Raimondo et al. 2004, Klemola et al. 2006). Intra-specific spatial synchrony and inter-specific temporal synchrony among populations may be affected by climatic conditions. The Moran effect is a specific mechanism for weather to synchronize populations over a large scale, because it states that independent populations are synchronized by regionally-correlated environmental disturbances (Moran 1953, Royama 1992). Factors such as dispersal and trophic bottom-up and topdown processes may cause smaller-scale patterns of spatial and temporal synchrony, respectively (Ranta et al. 1995a, 1995b, Liebhold et al. 2004). In northern Europe, two geometrid lepidop- 
terans, the winter moth (Operophtera brumata) and the autumnal moth (Epirrita autumnata) exhibit regular population cycles of 9-11 years (Tenow 1972, Enemar et al. 2004, Hogstad 2005, Klemola et al. 2006). Population cycles have either been synchronous between the species or the winter moth has lagged 1-3 years behind the autumnal moth (Tenow 1972, Hogstad 2005, Tenow et al. 2007, Klemola, T. et al. 2008). Thus, the population dynamics of the two moth species seem to be phase-locked but with a phase lag. Recently, the winter moth outbreak range has expanded from maritime to more continental areas, where previously only outbreaks by the autumnal moth occurred (Hagen et al. 2007, Jepsen et al. 2008, Klemola, T. et al. 2008). This overlap in the current distribution has already led to more intense and persistent defoliation of the main host of both species, i.e. the mountain birch (Betula pubescens ssp. czerepanovii).

Clearly phase-lagged moth population cycles were observed at one of our study sites (Hana, see below for details) and its surroundings in northernmost Norway. Severe outbreak densities with almost total defoliation of the mountain birch forest were observed for the autumnal moth in 2002 and 2003 (Klemola, T. et al. 2007, 2008). In 2004, the autumnal moth density had already started to decrease approaching practically zero density by 2007 (Fig. 1). The winter moth was rare until 2004, after which its density increased strongly, peaked in 2006 with continuing high densities in 2007 (Klemola, T. et al. 2008; Fig. 1). A similar pattern in population dynamics was also observed over large areas in northernmost Finland, e.g. in Kevo (see below), albeit at an order of magnitude lower densities (Klemola et al. 2007, pers. obs. by the authors). Despite the recent interest in birch geometrid moth dynamics (Tenow et al. 2007, Jepsen et al. 2008, Klemola, T. et al. 2008), the understanding of the underlying mechanisms for the phase-lagged population dynamics of these closely-related moth species remains poor. Klemola, T. et al. (2008) proposed that either the host utilization of the most important parasitoids and/or pathogens or the inducible resistance of the host tree have to be strictly species-specific to produce the population dynamics observed. However, their study did not support the latter

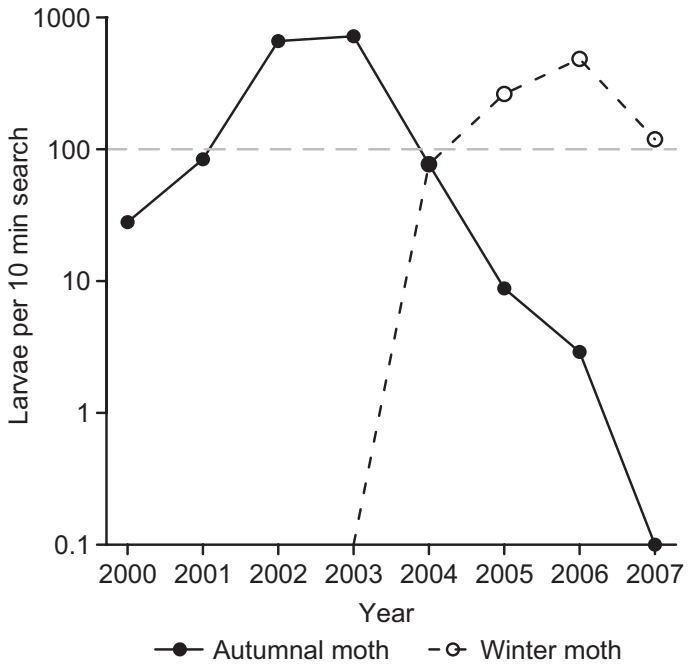

Fig. 1. Population density indices for the autumnal and winter moths (density estimation methods are given in Klemola, T. et al. 2008), illustrating clearly phase-lagged population dynamics between the species at Hana study site in northern Norway. The dashed horizontal line gives the approximated larval density required for clearly visible defoliation of mountain birch forest, which can be considered as a lower limit for the outbreak density.

hypothesis, while the role of the natural enemies remains largely unknown (Klemola, T. et al. 2008).

Assuming that the reproductive capacity is approximately the same for both moth species (i.e. potential for the intrinsic rate of the population increase does not differ between the species), the phase-lagged population dynamics may indeed be explained by predator/parasitoid-mediated mechanisms. Winter and autumnal moths are attacked, at least partly, by the same natural enemies, including generalist invertebrate and vertebrate predators as well as hymenopteran parasitoids, which are probably functional specialists of one or both moth species, due to the paucity of suitable alternative (geometrid) hosts in this northern ecosystem (Ruohomäki et al. 2000, Klemola et al. 2002). Generalist enemies, whose population densities do not follow those of the moths, create the most pronounced effects on moth population dynamics during low-density phases of the cycle due to saturation with increasing prey density (Berryman 1987, 2002, Turchin 2003, Enemar et al. 
2004). Thus, a preference by shared generalist enemies for one of the co-occurring moth species could delay its population increase in the early phases of the cycle. Conversely, specialist enemies with their delayed density-dependent numerical response to changes in moth densities mainly affect prey species in the late increase, peak and particularly crash phases of the population cycle (Berryman 2002, Turchin 2003). A preference or specialization of enemies for one moth species over another may thus contribute to an earlier collapse of the selected species.

Short-term apparent competition, i.e. where one of the co-existing prey species suffers relatively more from the shared natural enemies via their functional response (Holt 1977, Holt \& Kotler 1986), may also lead to asynchronous population dynamics. For example, it may lead to the delayed population increase of the preferred prey species. Although winter and autumnal moths probably do not exhibit direct exploitation or interference competition, except during the most severe outbreak conditions when the amount of foliage is a limiting factor, apparent competition via shared natural enemies may well occur within the system.

In this article, we formulate a new hypothesis to explain the seemingly phase-lagged population dynamics of winter and autumnal moths. We tested our hypothesis on reversed effects of specialist and generalist natural enemies with one-year field experiments on the larval and pupal stages, which seem most prone to mortality from natural enemies (Tanhuanpää et al. 1999, 2001, Klemola, N. et al. 2008, Hansen et al. 2009). Specifically, we estimated the probability of larval and pupal parasitism, as well as pupal predation of both species by vertebrates and invertebrates, under field conditions in 2007. Likewise, the existence of predator-mediated indirect effects between the moth species [if the interaction is mutually negative it is called shortterm apparent competition, if mutually positive it is called apparent mutualism (e.g. Teder \& Tammaru 2003)] was examined both for larvae and pupae. As supportive background data, we provide information on larval parasitism for both species from a study conducted in 2005 , when the population density of the autumnal moth had already started to decrease in Hana as compared with the still growing population density of the winter moth (Fig. 1). Instead of the above hypothesis, temporal differences in population growth to cyclic peaks may also result from the different reproductive capacities of the moth species. Therefore, we also compared the potential reproductive capacities as an approximation for the intrinsic growth rate of both moth species.

\section{Material and methods}

\section{Study system}

Autumnal and winter moths are univoltine and polyphagous geometrid lepidopterans found all over the Holarctic area (Tenow 1972). In the spring, hibernated eggs hatch and larvae go through five larval instars. Autumnal moth larvae feed freely on the leaves, whereas winter moths often live between leaves which are loosely spun together. Larvae of both species are often found on the same branch and sometimes even on the same leaf. The autumnal moth is substantially larger than the winter moth (Tenow 1972), and is typically one instar ahead of the winter moth in development (Mjaaseth et al. 2005). Autumnal moths pupate in the soil about one week earlier than winter moths (Mjaaseth et al. 2005), and their adults begin to emerge in mid-August, while adults of the winter moth eclose a few weeks later. In both species, adults rely solely on larvalderived resources and do not have to feed for either maintenance or reproduction. The pupal mass of the autumnal moth is positively correlated with the number of eggs, and could be used as a prediction of female fecundity (Haukioja \& Neuvonen 1985, Tammaru et al. 1996a, 1996b, Heisswolf et al.2009). To date, no details on the pupal mass-fecundity relationship of the northern Fennoscandian winter moth feeding on the mountain birch have been published (but see Roland \& Myers 1987). Autumnal moth females are relatively poor fliers (Ruohomäki et al. 2000), and those of the winter moth are totally flightless.

Parasitoid species attacking either the autumnal or the winter moth or both species, comprise at least 1 egg and 1 larval-pupal species each and approximately 15 larval and 5 pupal species, respectively (Ruohomäki 1994, Ruohomäki et 
al. 2000, Klemola et al. 2007, this study). Taxonomy and host specificity of these parasitoid species are rather poorly known. Other predators such as ants, beetles, spiders, insectivorous birds and small mammals (voles and shrews) are also known to attack the larvae and pupae of both species (Tanhuanpää et al. 1999, 2001, Ruohomäki et al. 2000, Enemar et al. 2004, Hogstad 2005). Earlier publications, however, have not revealed tight dependency of these predators on moth abundance. Thus we consider them as generalist predators.

\section{Study sites}

Larval and pupal exposures with a special experimental setup for revealing possible short-term apparent competition/mutualism were conducted in the vicinity of the Kevo Subarctic Research Station of the University of Turku in northern Finland $\left(69^{\circ} 45^{\prime} \mathrm{N}, 27^{\circ} 01^{\prime} \mathrm{E}\right)$ in summer 2007. One study site situated in northern Norway (Skippagurra: $70^{\circ} 09^{\prime} \mathrm{N}, 28^{\circ} 13^{\prime} \mathrm{E}, 65 \mathrm{~km} \mathrm{NE}$ from Kevo) was also employed for pupal exposures. In addition, we used the data from the summer 2007 experiments from a long-term pupal predation study conducted annually since 2000 in Hana $\left(70^{\circ} 14^{\prime} \mathrm{N}, 28^{\circ} 27^{\prime} \mathrm{E}, 80 \mathrm{~km} \mathrm{NE}\right.$ from Kevo). Here, pupal predation studies have normally concentrated solely on the autumnal moth, but the winter moth was also studied in 2007.

Cycle phases and natural larval abundances differed between the study sites. Density of both moth species was already low during the experiment in Kevo (Heisswolf et al. 2009, pers. obs. by the authors), while low autumnal moth and rather high winter moth larval abundances were still recorded at both Skippagurra and Hana. Due to the recent moth outbreaks at the Norwegian sites [Skippagurra: autumnal moths in 20032005 and winter moths in 2006, Hana: autumnal moths in 2002-2003 and winter moths in 20052007 (Fig. 1)], high post-outbreak parasitism rates could be expected due to delayed densitydependent parasitism (Tenow 1972, Ruohomäki et al. 2000). Study sites were dominated by the mountain birches [and pines (Pinus sylvestris) at two sites in Kevo], with dwarf shrubs (mainly
Vaccinium myrtillus, V. uliginosum, $V$. vitis-idaea and Empetrum nigrum ssp. hermaphroditum).

\section{Experimental larvae}

The parents of the experimental autumnal moths were either collected from the wild or obtained from cultures maintained for few generations in the laboratory and mated the previous autumn. Eggs were allowed to hatch in the laboratory and larvae were reared in groups inside 10-liter plastic containers. Fresh mountain birch leaves were provided at intervals of 1-4 days. Winter moths were collected as first and second instar larvae from the wild (Nuorgam, northern Finland, $70^{\circ} 04^{\prime} \mathrm{N}, 27^{\circ} 52^{\prime} \mathrm{E}, 50 \mathrm{~km}$ NE from Kevo) in early June and transported to the laboratory where they were reared similarly to that described above. For the pupal exposure experiments, larvae were allowed to pupate individually in plastic vials $(48 \mathrm{ml})$, which were halffilled with either moist Sphagnum moss or potting soil.

\section{Larval parasitism}

The larval parasitism rates for both moth species were also estimated in an observational study in 2005 , by collecting wild autumnal $(n=146)$ and winter moths $(n=85)$ from Hana. Larvae of both species were sampled twice (26 June and 4 July), so that both early ( $n=63$ for autumnal moth and $n=57$ for winter moth) and late $(n=83$ for autumnal moth, $n=28$ for winter moth) larval parasitism rate could be estimated (Klemola et al. 2007). Larvae were transported to the laboratory and reared individually in vials (48 $\mathrm{ml})$ until they pupated or parasitoid larvae emerged. Individuals were checked in late summer and again in next spring for parasitoids emerging from prepupa or pupa.

To estimate larval parasitism rates in the experimental study, five study sites with a mean inter-site distance of $860 \mathrm{~m}$ (range 200-1880 m) and mean altitude (a.s.1.) of $120 \mathrm{~m}$ (range 85-140 m) were established in the Kevo area in 2007. Each study site consisted of three treatment plots with an inter-plot distance of approximately 
A

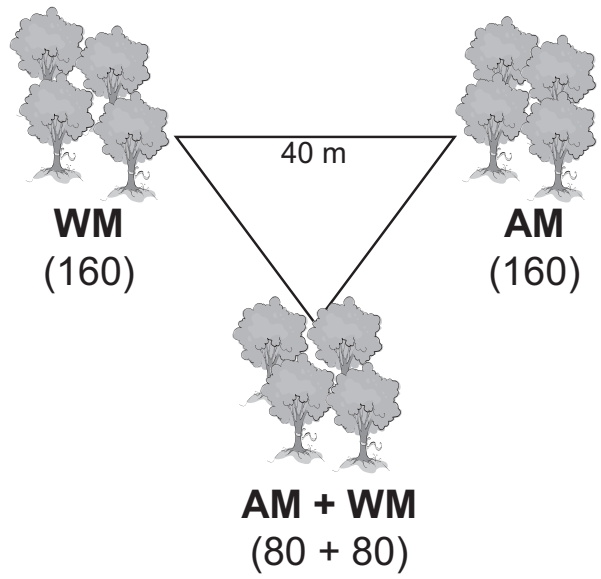

B

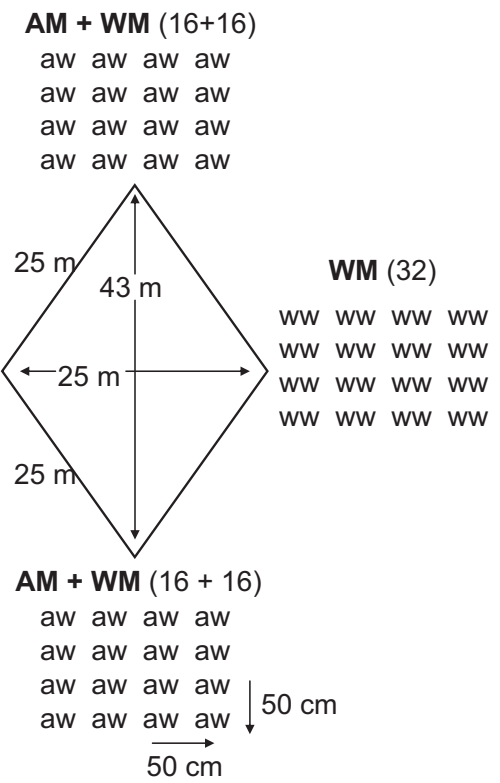

Fig. 2. Study design for short-term apparent competition/mutualism experiments between autumnal and winter moth (A) larvae and (B) pupae with single-species and mixed-species plots (AM = autumnal moths only, $\mathrm{WM}=$ winter moths only and $\mathrm{AM}+\mathrm{WM}=$ both species). The number of exposed larvae/pupae per treatment plot is shown in parentheses. 40 larvae were used on each tree for larval exposure experiments. For the pupal exposure tests, each treatment plot contained 16 open-topped cages with two pupae in each $(\mathrm{aa}=$ two autumnal moths, ww = two winter moths, aw = one autumnal and one winter moth inside a cage). Distances between treatment plots and between cages in the pupal exposure tests are shown.

$40 \mathrm{~m}$. Treatments were as follows: a mixedspecies treatment consisting of both moth species and a single-species treatment each of the autumnal and winter moth (Fig. 2A). This study design with single- and mixed-species plots enabled the estimation of possible short-term larval apparent competition/mutualism.

Within each treatment plot, four poly-cormic, bush-like mountain birches (2-3 $\mathrm{m}$ in height), i.e. typical ones for the study area, were chosen not further than four meters from the plot center. Two parasitoid-proof, branch-wide mesh bags, containing 20 larvae (10 of each species in the mixed treatment), were placed on separate branches of each chosen tree. At four study sites, larvae were placed on the trees inside mesh bags on 10 June 2007. Due to practical reasons, larvae at the fifth site were put directly onto the branches without mesh-bags on 15 June 2007. On the same day, the mesh bags were also removed at the four previously established study sites. Thus, the exposure to larval parasitism started simultaneously at all five study sites. The developmental stage of experimental larvae was similar to those in the wild, i.e. the larvae were in their second or third instar in the beginning of the exposure.

Due to the expected high disappearance rate resulting from the failure of larval establishment, migration and predation, a total of 2400 larvae, i.e. 5 sites $\times 3$ plots $\times 4$ trees $\times 2$ bags $\times 20$ larvae, were released. However, because of the elaborate experimental setup needed to estimate larval predation (see Tanhuanpää et al.2001), we concentrated on larval parasitism only.

After eight days of exposure, all the larvae found and collected from the experimental trees were transferred to the laboratory, where they were reared individually in plastic vials $(48 \mathrm{ml})$. Most of the collected larvae were in their fourth or fifth instar but some were still in the third instar. The larvae were checked daily for possible parasitoid emergence and were provided fresh leaves every second or third day. In case no parasitoid emerged during larval development, prepupating individuals were allowed to pupate individually inside vials containing moist Sphagnum moss. Approximately ten days after pupation individuals were again checked for late larval parasitoids emerging from the prepupae. Pupae from which an adult moth did not emerge in the autumn were retained intact in a refrigerator until the following spring when they were rechecked for possible larval-pupal parasitoids. 


\section{Pupal parasitism and predation}

To estimate pupal parasitism and predation rates, we established three study sites. Two sites were located near Kevo (with an inter-site distance of $100 \mathrm{~m}$ ), with the third at Skippagurra. Each study site consisted of four treatment plots (comprising a diamond-shaped design with a side length of about $25 \mathrm{~m}$ ) as follows: two mixed-species treatments consisting of both the autumnal and winter moth pupae at the furthest located opposite corners, a single-species treatment each of autumnal and winter moths at the remaining corners (Fig. 2B). As with the larval experiments, this study design enabled the estimation of possible short-term apparent competition/mutualism for the moth pupae.

Ten-day-old experimental pupae were sexed and weighed (which required the removal of the pupal cocoon), and exposure started at the beginning of July. Each treatment plot consisted of 16 cage stations in a $4 \times 4$ grid with intervals of $50 \mathrm{~cm}$ (Fig. 2B). Moreover, to acquire more information about the preferences of the pupal enemies, three parallel transects of 33, 33 and 34 mixed-species cage stations at one meter intervals comprising a total of 200 pupae were established at Skippagurra. In the mixed-species treatment plots and transects, each plastic cage contained of one pupa of both species, whereas in the single-species treatment plots, both pupae belonged to the same species. In total, 584 pupae were used, i.e. 3 sites $\times 4$ plots $\times 16$ cages $\times 2$ pupae +200 pupae in transects.

In the single-species plots, a plastic mesh wall separating the pupae inside the cage was used to facilitate the later identification of individuals. Treatment plots and transects were marked with colored paper string and each cage station with a $20 \mathrm{~cm}$ long wooden stick. The plastic cages $(6 \times$ $3 \times 4 \mathrm{~cm}$ ) were open-topped with a $0.5 \mathrm{~cm}$ mesh. Cages were filled with moist Sphagnum moss, marked with identification codes for the pupae and were buried a few centimeters deep in the moss layer (Klemola et al. 2007).

In Hana, the pupal predation study followed different, already established methods (Tanhuanpää et al. 1999). Here, we did not aim to test apparent competition/mutualism and pupae were neither weighed nor sexed. Thus, their cocoon stayed intact. A total of 150 autumnal and 50 winter moth pupae were exposed to pupal enemies for five weeks. This study site had five plots situated ca. 50-100 m apart, with four parallel transects ( 3 for autumnal moths and 1 for winter moths) approximately $10 \mathrm{~m}$ apart in each plot. In each transect, ten pupae inside their cocoons were buried $2-3 \mathrm{~cm}$ into the soil or moss layer at one meter intervals. The pupation substrate (potting soil) included glitter to enable easier retrieval of the cocoons after the exposure trials (Tanhuanpää et al. 1999).

After two weeks (five weeks in Hana), pupae were transferred to the laboratory where their fates (survived, parasitized or preyed upon) were determined. Invertebrate predation was identified due to specific feeding marks on the pupa (Frank 1967a, 1967b, Tanhuanpää et al. 1999). Vertebrate predation was assumed to have occurred when the pupa had disappeared (Tanhuanpää et al. 1999). In many cases of vertebrate predation, the moss inside the cage was disturbed, included the droppings of small mammals (voles and shrews) and the plastic cages were often partly broken also. The status of parasitism was unknown for the pupae that were attacked by predators and these were considered as missing values in statistical analyses. Similarly, the status of invertebrate predation was unknown for those pupae which were assumed to have been attacked by vertebrate predators. In contrast, both the successfully parasitized pupae as well as those preyed upon by invertebrates were assumed to have survived from vertebrate predation.

\section{Fecundity estimation of the winter moth}

The winter moths $(n=112)$ that survived the pupal exposure experiment were kept at $15^{\circ} \mathrm{C}$ in growth chambers until they eclosed. The newlyeclosed females $(n=39)$ and males were randomly mated in $100 \mathrm{ml}$ vials and females were allowed to oviposit onto a roll of tissue paper. The total number of eggs (oviposited eggs and eggs remaining inside the female after its death) was considered as the potential fecundity of the female (see detailed methods in Heisswolf et al. 2009). These results were compared with the fecundity results reported earlier for the autum- 
nal moth (Kaitaniemi et al. 1999, Heisswolf et al. 2009).

\section{Statistical analyses}

Due to the binomial distribution of the survival data, generalized linear mixed models (GLMM: using the GLIMMIX procedure in SAS statistical software, ver. 9.1) with a binomial error structure and a logit link function were applied for the probability analyses of larval and pupal parasitism and predation events. In order to examine apparent competition/mutualism in both larval and pupal stages, GLMM procedures were conducted with the main effects of treatment (single-species or mixed-species), moth species (winter or autumnal moth) and sex (male or female; available only for pupae), as well as all possible interactions between them. Study site was treated as a random effect in the analyses. Pupae buried in transects at Skippagurra were added into other GLMM tests to investigate the overall probabilities of pupal predation and parasitism between the moth species. Generalized linear models without a random effect were applied to data of the pupae exposed at Hana. Due to very high inter-site variation in pupal vertebrate predation, the study sites were also analyzed separately. Back-transformed least-squares mean estimates (LS means) and odds ratios (OR) were used for illustrating between-species differences in parasitism and predation probabilities.

GLMM procedures were also conducted to study the effects of the pupal mass on predation and parasitism. As pupal mass is a species- and sex-specific variable (autumnal moth pupae were about two times heavier than winter moth pupae; data not shown), these analyses were done sepa- rately for both species. The relationship between the pupal mass and number of produced eggs of the winter moths was analyzed with a simple linear regression (the GLM procedure in SAS).

\section{Results}

\section{Larval and pupal parasitism}

In 2005, the larval parasitism rate for the autumnal moth was about $3 \%$ in the early and $45 \%$ in the late sample (Table 1), whereas no single winter moth larva was found to be parasitized in Hana that year. Two different parasitoid species were reared from the autumnal moth (Table 1).

In 2007, of those larvae released (1200 autumnal and 1200 winter moths) in the study plots, a total of $73(6.1 \%)$ autumnal and 128 $(10.7 \%)$ winter moth larvae were found and checked for parasitoids. The probability of larval parasitism was significantly higher for the autumnal than for the winter moth [species: $F_{1,194}=11.12, p=0.001, \mathrm{OR}=3.4(95 \% \mathrm{CI}=1.6$ to 6.9); Fig. 3]. Treatments, i.e. single-species versus mixed-species, including the interaction between species and treatment had no statistically significant effect on the probability of parasitism, indicating no short-term apparent competition or mutualism for larvae (treatment: $F_{1,194}=$ $1.72, p=0.19$, treatment $\times$ species: $F_{1,194}=2.79$, $p=0.10)$.

Of the pupal exposures conducted at both Kevo and Skippagurra, only a single autumnal moth pupa was parasitized by Pimpla flavicoxis, thus, preventing further analyses on parasitism rates or apparent competition/mutualism. In Hana, pupal parasitism rates were higher, but no significant difference was found between winter

Table 1. Frequency and percentage of larval parasitism by hymenopteran parasitoids reared from autumnal moth larvae collected from Hana in 2005. None of the winter moth larvae were parasitized either in early (57 larvae collected) or in late (28 larvae collected) sample. Both C. salebrosa and Z. deceptor are solitary endoparasitoids and belong to the family Braconidae.

\begin{tabular}{lclrl}
\hline Sample & Sample size & Parasitoid species & Frequency & Percentage \\
\hline Early larval & 63 & Cotesia salebrosa & 2 & 3.2 \\
Late larval & 83 & Cotesia salebrosa & 8 & 9.6 \\
& & Zele deceptor & 29 & 34.9 \\
\hline
\end{tabular}


and autumnal moths $\left(F_{1,143}=0.18, p=0.67\right.$; Fig. $3)$. The larval and pupal parasitoid species of this study correspond to the parasitoid fauna found during the latest increase and peak phases of the cycle (Klemola et al. 2007, Klemola, N. et al. 2008) and are listed in Table 2.

\section{Invertebrate and vertebrate pupal predation}

The effects of treatment and treatment $\times$ species interaction were non-significant, indicating no short-term apparent competition or mutualism via invertebrate $\left(F_{1,263}=0.20, p=0.66\right.$ for treatment, $F_{1.263}=0.18, p=0.67$ for treatment $\times$ species $)$ and vertebrate $\left(F_{1,378}=0.41, p=0.52\right.$ for treatment, $F_{1,378}=0.55, p=0.46$ for treatment $\times$ species) pupal predators. Also sex had no significant effect on pupal predation $\left(F_{1,262}=1.59, p=\right.$ 0.21 for invertebrate predation and $F_{1,377}=0.57$, $p=0.45$ for vertebrate predation). However, the probabilities of pupal invertebrate predation showed inter-specific differences $\left(F_{1,263}=13.82\right.$, $p=0.0002$, LS means \pm SE: $0.29 \pm 0.07$ and 0.11 \pm 0.04 , respectively for the winter and autumnal moths). The probability of vertebrate predation also differed between species $\left(F_{1,378}=10.42, p\right.$ $=0.0013, \mathrm{LS}$ means \pm SE: $0.04 \pm 0.09$ and 0.24 \pm 0.4 , respectively for the winter and autumnal moths). Therefore, to revise the predation prob-

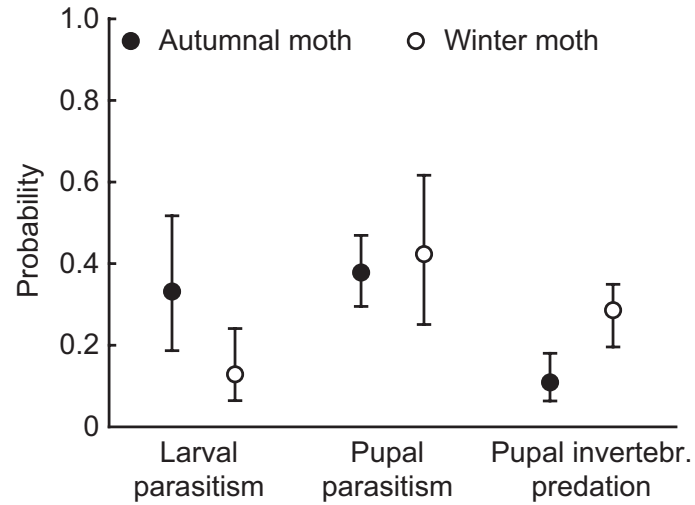

Fig. 3. Probability of larval parasitism, pupal parasitism (data from Hana study site only), and pupal invertebrate predation of the autumnal and winter moth (backtransformed least-squares means with $95 \% \mathrm{Cl}$ from statistical models).

ability of moth species with the largest available sample sizes, another set of models was conducted, which included also those pupae buried in transects.

In this larger sample, winter moth pupae were approximately three times more vulnerable to invertebrate predation than those of the autumnal moth $\left[F_{1.454}=23.14, p<0.0001\right.$, OR $=3.3(95 \% \mathrm{CI}=2.0$ to 5.3), Fig. 3]. Although the data from Hana showed a similar tendency, it was not significant $\left(F_{1.174}=2.26, p=0.13\right.$; LS means \pm SE: $0.26 \pm 0.07$ and $0.15 \pm 0.03$, respectively for the winter and autumnal moths).

Table 2. Frequency and percentage of larval and pupal parasitism by hymenopteran parasitoids reared from 73 autumnal (E. aut.) and 128 winter (O. bru.) moth larvae and 116 autumnal and 26 winter moth pupae in 2007. Pupal parasitoids are from the Hana study site only. Parasitoid guild, species, family [Ichneumonidae (Ich), Braconidae (Bra) or Eulophidae (Eul)], as well as type of the parasitoid [solitary (S), gregarious (G), endoparasitoid (En) or ectoparasitoid $(\mathrm{Ec})]$ are shown.

\begin{tabular}{|c|c|c|c|c|c|c|c|}
\hline \multirow[t]{2}{*}{ Parasitoid guild } & \multirow[t]{2}{*}{ Parasitoid sp. } & \multirow[t]{2}{*}{ Family } & \multirow[t]{2}{*}{ Type } & \multicolumn{2}{|c|}{ E. aut. } & \multicolumn{2}{|c|}{ O. bru. } \\
\hline & & & & Freq. & Percentage & Freq. & Percentage \\
\hline \multirow[t]{6}{*}{ Larval parasitoids } & Agrypon flaveolatum & Ich & $\mathrm{S}, \mathrm{En} \mathrm{n}^{\mathrm{a}}$ & 11 & 15.1 & - & - \\
\hline & Eulophus larvarum & Eul & $\mathrm{G}, \mathrm{Ec}$ & 11 & 15.1 & 10 & 7.8 \\
\hline & Cotesia salebrosa & Bra & S, En & 1 & 1.4 & 7 & 5.5 \\
\hline & Phobocampe sp. & Ich & S, En & - & - & 2 & 1.6 \\
\hline & Aleiodes cf. gastritor & Bra & S, En & 2 & 2.7 & - & - \\
\hline & E. larvarum $+A$. gastritor ${ }^{b}$ & & & 1 & 1.4 & - & - \\
\hline \multirow[t]{3}{*}{ Pupal parasitoids } & Pimpla flavicoxis & Ich & $\mathrm{S}, \mathrm{En}$ & 23 & 19.8 & 2 & 7.7 \\
\hline & Cratichneumon viator & Ich & S, En & 9 & 7.8 & 5 & 19.2 \\
\hline & Cratichneumon sp. & Ich & S, En & 6 & 5.2 & 1 & 3.8 \\
\hline
\end{tabular}

${ }^{\text {a }}$ Larval-pupal parasitoid, ${ }^{\mathrm{b}}$ Multiparasitism. 


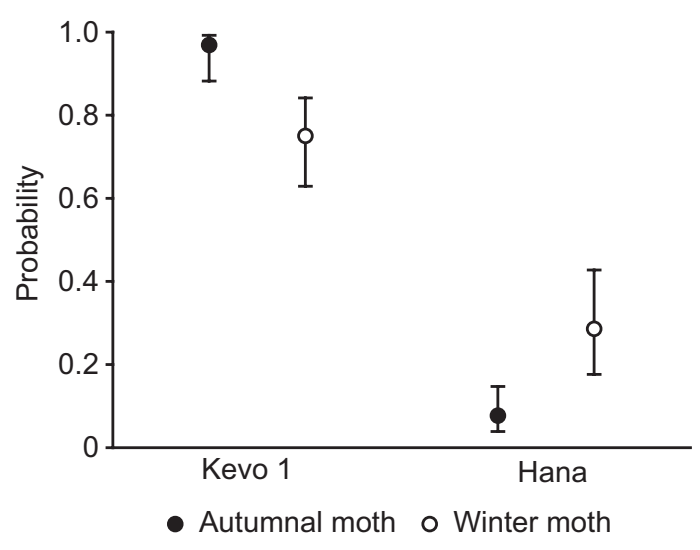

Fig. 4. Probability of pupal vertebrate predation at Kevo (Site 1) and in Hana (back-transformed least-squares means with $95 \% \mathrm{Cl}$ from statistical models).

Furthermore, although a highly significant negative relationship was found between invertebrate predation and pupal mass in the winter moth $\left(F_{1,235}=12.83, p=0.0004\right.$, slope \pm SE: $-0.11 \pm$ $0.03)$, this relationship was not significant for the autumnal moth $\left(F_{1,219}=0.01, p=0.93\right.$, slope \pm SE: $-0.002 \pm 0.02)$.

A notable difference in vertebrate pupal predation probabilities was observed between the study sites, with the highest predation rate (85.9\% of pupae in two weeks) occurring at site 1 in Kevo. Here, vertebrate predators attacked significantly more autumnal moth pupae than those of the winter moth $\left[F_{1,126}=9.10, p=\right.$ $0.0031, \mathrm{OR}=10.33$ (95\% CI = 2.2 to 47.8 ); Fig. 4]. By contrast, $38.6 \%$ of pupae were preyed upon by vertebrates in five weeks at the Hana study site, where winter moth pupae suffered significantly higher predation rates that those of the autumnal moth $\left[F_{1,151}=10.45, p=0.0015\right.$; $\mathrm{OR}=4.8$ (95\% CI $=1.8$ to 12.5$)$; Fig. 4]. Predation rates were markedly lower at the other two sites in two weeks $(2.3 \%$ and $0 \%$, respectively for the autumnal and winter moths at site 2 in Kevo and $1.2 \%$ for both species in Skippagurra) and did not show any inter-specific differences $\left(F_{1,126}<0.1, p=0.98\right.$ and $F_{1,322}=0, p=1$, respectively for site 2 in Kevo and Skippagurra).

\section{Fecundity of the winter moth}

The mean $( \pm$ SE) egg number for winter moth

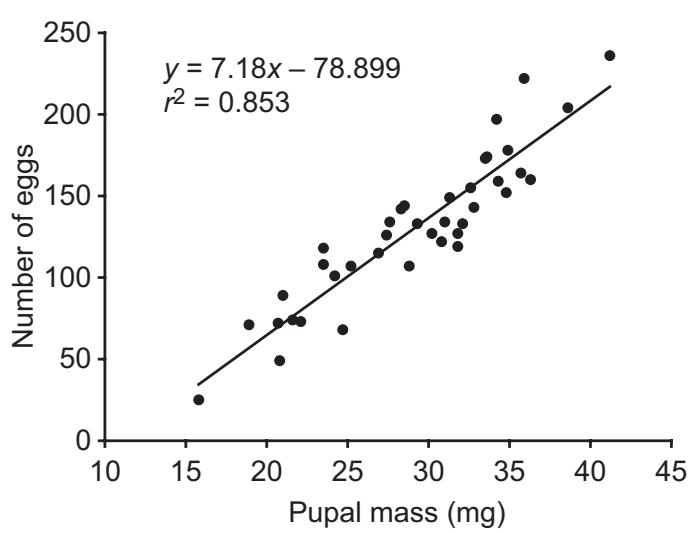

Fig. 5. Relationship between total egg numbers (potential fecundity) and pupal mass of the winter moth, Operophtera brumata $(n=39)$.

females $(n=39)$ was $130.4 \pm 7.3$ and there was a clear positive relationship between pupal mass and egg numbers $\left(F_{1,37}=215.04, p<0.0001\right.$, slope \pm SE: $7.18 \pm 0.49$; Fig. 5), as previously reported for the winter moth also on oak and apple trees in Canada (Roland \& Myers 1987).

\section{Discussion}

We found that both winter and autumnal moth populations were significantly and reversely affected by specialist and generalist natural enemies. Specialized larval parasitoids attacked the autumnal moth more than the winter moth, whereas the opposite was true for the generalist invertebrate predators of pupae (Fig. 3). The effect of vertebrate predators on both moth species was site-specific and varied in both intensity and direction (Fig. 4). These results suggest a potential explanation for observed phase-lagged population cycles of autumnal and winter moths in northern Fennoscandian birch forests.

The reproductive capacity of both species appears to be similar. In this study, the mean number of eggs for female winter moths was about 130 (Fig. 5), whereas previous studies reported from 119 to 150 eggs for the autumnal moth (Kaitaniemi et al. 1999, Heisswolf et al. 2009). This indicates that intrinsic population growth rates probably cannot explain the phaselagged population increases in autumnal and winter moths. Moreover, an alternative explana- 
tion is particularly required for the time difference in population collapses observed in these moth species.

In addition, a more general result of our study was that short-term apparent competition/ mutualism via shared parasitoids and pupal predators did not seem to play a major role in the system studied. We cannot however exclude the possibility that apparent competition may operate via other natural enemies at the employed spatial scale, via studied or other natural enemies in a larger spatial scale, or in longer, transgenerational time-scales (Holt 1977, Holt \& Lawton 1994). Adult parasitoids, for example, may fly over fairly large areas, and consequently, "regional" abundance of the host species may be more important for parasitoids than local abundance manipulated in the present study. Another possibility for indirect interaction among moth species is provided by plant-mediated competition, which operates through decreased nutritional value by the induced resistance of the shared host plant (Harrison \& Karban 1986, Denno et al. 1995).

Pupal parasitism seems to be an unlikely candidate for causing the phase lag in population dynamics of autumnal and winter moths, as there were neither inter-specific differences in pupal parasitism probabilities nor parasitoid species involved at the only study site (Hana) which showed high amounts of pupal parasitism (Fig. 3). We could not estimate species-related differences in pupal parasitism at the other study sites due to the virtually zero pupal parasitism rates. This might be caused by few naturally occurring parasitoids or it may be an artifact of the experimental setup used, possibly lowering the explanatory power of the study. Pupae were buried in the soil inside their cocoons for five weeks at Hana, whereas at the other sites pupae without their cocoons were exposed for a period of only two weeks. Thus, it is, for example, possible that the cocoons provide important olfactory cues for pupal parasitoids when searching for a host (Vinson 1976).

Vertebrate predation can have a major impact on pupal densities. However, in this study its effect varied markedly between the study sites (Fig. 4), thus making conclusions about vertebrate prey preference difficult. Most of the pupae killed by vertebrates were observed at a single study site, where the predation rate was extremely high. This may suggest a potentially strong local effect of voles and shrews upon moth populations. On the other hand, the experimental cages were partly visible and marked with wooden sticks so it is possible that vertebrates learned how to find cages at this site. Vertebrate predation rates from the other study sites were substantially lower and were also more consistent with both published (Tanhuanpää et al. 1999) and unpublished results (our unpublished long-term data on autumnal moths in Hana). Therefore, we do not consider vertebrate predation as a major cause for the phase-lagged population cycles either.

Comparing larval parasitism, we found a first candidate mechanism that could lead to the phase-lagged moth cycles. In 2005, the population density of the autumnal moth had already started to decrease in Hana, whereas the winter moth population density was still increasing. In that year, there was also a notable difference in larval parasitism rates, as almost $30 \%$ of the autumnal moth larvae were parasitized in Hana, while there was not a single parasitized winter moth larva (Table 1). This result could be explained by a parasitoid preference for the autumnal moths and provides a possible mechanism for the divergence in population dynamics.

In the study year 2007, larval hymenopteran parasitoids parasitized about three times more autumnal than winter moths in Kevo area (Fig. 3). Despite the short-term larval exposure to parasitoids, we succeeded to sample both early and late larval parasitoids commonly found on the study area (see Klemola et al. 2007). Exception was Zele deceptor, which was the dominant parasitoid species of the autumnal moth in Hana in 2005 (Table 1). These results emphasize that different parasitoid species can be important in different areas and in different years (see Gripenberg \& Roslin 2007).

Parasitoids are virtually absent from the early increase phase but proliferate at the peak and post-peak phases of the cycle, when parasitism rates can approach $100 \%$ at least in the autumnal moth population (Tenow 1972, Bylund 1995, Ruohomäki et al. 2000, Klemola et al. 2007, Klemola, N. et al. 2008, K. Ruohomäki \& T. 
Klemola unpubl. data). Parasitoids as functional specialist are potentially capable of driving population cycles due to delayed density-dependence (Klemola et al. 2002). Thus, their uneven host utilization may contribute to an earlier collapse of the autumnal moth population, but also simultaneously allow a further increase in winter moth density. Winter moths will then peak after the autumnal moth population has already collapsed. At this stage, when the winter moth is the only abundant geometrid in the system, a large proportion of the shared natural enemies are forced to use them as a host/prey and consequently may contribute to the subsequent collapse of winter moth density. However, the host specificity of an egg parasitoid (Telenomus cf. laeviceps, Hymenoptera: Scelionidae), which has recently been found to parasitize both moth species (K. Ruohomäki \& T. Klemola unpubl. data), and maybe also the host specificity of some pathogens remain to be studied to fully cover the specialist natural enemy assemblage of autumnal and winter moths.

In 2005, most of the larval parasitism of the autumnal moth was caused by $Z$. deceptor while in 2007, the largest larval parasitoid, i.e. Agrypon flaveolatum, caused the most interspecific differences in larval parasitism. These two species were found to be specialists for the autumnal moth in this study system. This specialization was supported experimentally in laboratory tests where parasitoid females were allowed to selectively parasitize exposed larvae of both winter (ca. 400 for A. flaveolatum and ca. 300 for Z. deceptor) and autumnal (ca. 400 for $A$. flaveolatum and ca. 300 for Z. deceptor) moths. The results showed that none of the winter moth larvae were successfully parasitized, while 55 autumnal moth larvae were parasitized by $A$. flaveolatum and 103 by Z. deceptor (A. Heisswolf unpubl. data). The specialization of $A$. $f l a-$ veolatum on the autumnal moth was surprising, because it has been used as a biological control agent against winter moths in Canada (Roland \& Embree 1995). One possibility is that the local strains of A. flaveolatum and Z. deceptor may have become specialized in the autumnal moth, because it is resident in the area, whereas the winter moth has occurred there only sporadically, except during the present outbreak. Further work is thus needed to clarify why these parasitoid species failed to parasitize winter moths in this study.

Invertebrate pupal predation by generalist invertebrates may be a second mechanism which contributes to the population cycle asynchrony of the two moth species. The predation probability by generalist invertebrates was about three times higher for the winter than for the autumnal moth, which is exactly the reverse of the impact of larval parasitoids (Fig. 3). Commonly, the effects of generalist enemies on the dynamics of their lepidopteran prey populations seem to vary according to the cycle phase, being most pronounced when the density of prey is relatively low, i.e. at the bottom and early increase phases (e.g. Morris et al. 1958, Campbell \& Sloan 1977, Holmes et al. 1979, Berryman 1987, Elkinton et al. 1996). This effect weakens at the late increase and peak phases of the prey cycle due to predator saturation with increasing prey density (Morris et al. 1958, Enemar et al. 2004). This is congruent with the general synoptic model for outbreak insects suggesting that low-density populations are maintained by generalist predators with constrained abilities to respond to increases in the density of their prey (Southwood \& Comins 1976). Furthermore, although direct density-dependent mortality by generalists has a stabilizing effect on prey populations, they cannot generate high-amplitude cycles or terminate outbreaks (Hanski et al. 1991, Tanhuanpää et al. 2001, Klemola et al. 2002). However, generalists may contribute to the phase-lagged population dynamics of the studied moth species by causing higher mortality for the winter moth and also by delaying its population growth at the early phases of the cycle. This may simultaneously allow the relatively more rapid population size increase for the autumnal moth as compared with the winter moth.

One potential reason for the preference of invertebrate predators for winter moths could be the differences in the thickness and hardiness of the pupal cuticle. This feature has a crucial effect on the food selection of the invertebrate predators (Frank 1967a, 1967b) and might explain the lower invertebrate predation of the autumnal moth with its thicker pupal cuticle. Cuticle thickness may also explain size-dependency in the 
predation of winter moth pupae. In this species, smaller pupae were more vulnerable to invertebrate pupal predators than larger ones.

This experimental study was conducted simultaneously at three distinct sites where somewhat different cycle phases prevailed. However, for further investigations on the phase-lagged population dynamics and our new hypothesis, we recommend that the total impact by parasitoids and predators should be derived by considering the ratio of enemy preferences between the prey species in different cycle phases, instead of using absolute predation/parasitism probabilities. This is due to the cycle-phase dependent variation in moth mortality by specialist and generalist enemies. Optimally, predation and parasitism rates by all natural enemies should be followed through 1-2 whole population cycles which would demand more than a ten-year effort.

We conclude that the reversed effects of specialist and generalist natural enemies provide a potential explanation for the observed phase-lagged population dynamics of the cyclic winter and autumnal moths. However, more studies concerning the responses of different predators and parasitoids, preferably accompanied by model-based approaches are needed to achieve a more comprehensive understanding of the mechanisms behind the phenomenon. In this article we have provided novel empirical data on predation and parasitism of the autumnal and winter moths. Furthermore, we have put forward a verbal formulation of a new hypothesis on two candidate mechanisms that may explain, at least partially, the phase-lagged population dynamics of the autumnal and winter moths in northern Fennoscandia. A more formal synthesis and detailed exploration of the suggested hypothesis based on mathematical modeling will be presented in a succeeding study (T. Ammunét unpubl. data).

\section{Acknowledgements}

We thank Tommi Andersson, Aino Kalske, Saara Koutaniemi, Kukka Kyrö and Hanna Urtti for their great help with this study. Jeffrey A. Harvey, Rolf A. Ims, Lauri Oksanen, Toomas Tammaru and two anonymous referees are thanked for their comments on earlier drafts of the manuscript, Kevin O'Brian for English improvements and the Kevo Subarctic
Research Station for good working facilities. Reijo Jussila, Heinz Schnee, Mark R. Shaw, Ilari E. Sääksjärvi and Veli Vikberg are gratefully thanked for their help in parasitoid identification. This research was supported financially by the Academy of Finland (decision numbers 111195 and 129143 to T.K.), Turku University Foundation, Finnish Concordia Fund and Lapland Regional Fund of Finnish Cultural Foundation (grants to N.K.).

\section{References}

Berryman, A. A. 1987: The theory and classification of outbreaks. - In: Barbosa, P. \& Schultz, J. C. (eds.), Insect outbreaks: 3-29. Academic Press, San Diego.

Berryman, A. A. 2002: Population cycles: the case for trophic interactions. - Oxford University Press, USA.

Bylund, H. 1995: Long-term interactions between the autumnal moth and mountain birch: the roles of resources, competitors, natural enemies and weather. - Ph.D. thesis, Swedish University of Agricultural Sciences, Uppsala.

Campbell, R. W. \& Sloan R. J. 1977: Natural regulation of innocuous gypsy moth populations. - Environmental Entomology 6: 315-322.

Denno, R. F., McClure, M. S. \& Ott, J. R. 1995: Interspecific interactions in phytophagous insects: competition reexamined and resurrected. - Annual Review of Entomology 40: 297-331.

Elkinton, J. S., Healy, W. M., Buonaccorsi, J. P., Boettner, G. H., Hazzard, A. M., Smith, H. R. \& Liebhold, A. M. 1996: Interactions among gypsy moths, white-footed mice, and acorns. - Ecology 77: 2332-2342.

Enemar, A., Sjöstrand, B., Andersson, G. \& von Proschwitz, T. 2004: The 37-year dynamics of a subalpine passerine bird community, with special emphasis on the influence of environmental temperature and Epirrita autumnata cycles. - Ornis Svecica 14: 63-106.

Frank, J. H. 1967a: The insect predators of the pupal stage of the winter moth, Operophtera brumata (L.) (Lepidoptera: Hydriomenidae). - Journal of Animal Ecology 36: 375-389.

Frank, J. H. 1967b: The effect of pupal predators on a population of winter moth, Operophtera brumata (L.) (Hydriomenidae). - Journal of Animal Ecology 36: 611-621.

Gripenberg, S. \& Roslin, T. 2007: Up or down in space? Uniting the bottom-up versus top-down paradigm and spatial ecology. Oikos 116: 181-188.

Hagen, S. B., Jepsen, J. U., Ims, R. A. \& Yoccoz, N. G. 2007 : Shifting altitudinal distribution of outbreak zones of winter moth Operophtera brumata in sub-arctic birch forest: a response to recent climate warming? - Ecography 30: 299-307.

Hansen, N. M., Ims, R. A. \& Hagen, S. B. 2009: No impact of pupal predation on the altitudinal distribution of autumnal moth and winter moth (Lepidoptera: Geometridae) in sub-arctic birch forest. - Environmental Entomology 38: 627-632.

Hanski, I., Hansson, L. \& Henttonen, H. 1991: Specialist 
predators, generalist predators, and the microtine rodent cycle. - Journal of Animal Ecology 60: 353-367.

Harrison, S. \& Karban, R. 1986: Effects of an early-season folivorous moth on the success of a later-season species, mediated by a change in the quality of the shared host, Lupinus arboreus Sims. - Oecologia 69: 354-359.

Haukioja, E. \& Neuvonen, S. 1985: The relationship between size and reproductive potential in male and female Epirrita autumnata (Lep., Geometridae). - Ecological Entomology 10: 267-270.

Heisswolf, A., Klemola, T., Andersson, T. \& Ruohomäki, K. 2009: Shifting body weight-fecundity relationship in a capital breeder: maternal effects on egg numbers of the autumnal moth under field conditions. - Bulletin of Entomological Research 99: 73-81.

Hogstad, O. 2005: Numerical and functional responses of breeding passerine species to mass occurrence of geometrid caterpillars in a subalpine birch forest: a 30-year study. - Ibis 147: 77-91.

Holmes, R. T., Schultz, J. C. \& Nothnagle, P. 1979: Bird predation on forest insects: an enclosure experiment. Science 206: 462-463.

Holt, R. D. 1977: Predation, apparent competition, and the structure of prey communities. - Theoretical Population Biology 12: 197-229.

Holt, R. D. \& Kotler, B. P. 1986: Short-term apparent competition. - American Naturalist 130: 412-430.

Holt, R. D. \& Lawton, J. H. 1994: The ecological consequences of shared natural enemies. - Annual Review of Ecology and Systematics 25: 492-520.

Jepsen J. U., Hagen, S. B., Ims, R. A. \& Yoccoz, N. G. 2008: Climate change and outbreaks of the geometrics Operophtera brumata and Epirrita autumnata in subarctic birch forest: evidence of a recent outbreak range expansion. - Journal of Animal Ecology 77: 257-264.

Kaitaniemi, P., Ruohomäki, K., Tammaru, T. \& Haukioja, E. 1999: Induced resistance of host tree foliage during and after a natural insect outbreak. - Journal of Animal Ecology 68: 382-389.

Klemola, N., Kapari, L. \& Klemola, T. 2008: Host plant quality and defence against parasitoids: no relationship between levels of parasitism and a geometrid defoliator immunoassay. - Oikos 117: 926-934.

Klemola, T., Andersson, T. \& Ruohomäki, K. 2008: Fecundity of the autumnal moth depends on pooled geometrid abundance without a time lag: implications for cyclic population dynamics. - Journal of Animal Ecology 77: 597-604.

Klemola, T., Huitu, O. \& Ruohomäki, K. 2006: Geographically partitioned spatial synchrony among cyclic moth populations. - Oikos 114: 349-359.

Klemola, T., Klemola, N., Andersson, T. \& Ruohomäki, K. 2007: Does immune function influence population fluctuations and level of parasitism in the cyclic geometrid moth? - Population Ecology 49: 165-178.

Klemola, T., Tanhuanpää, M., Korpimäki, E. \& Ruohomäki, K. 2002: Specialist and generalist natural enemies as an explanation for geographical gradients in population cycles of northern herbivores. - Oikos 99: 83-94.

Liebhold, A., Koenig, W. D. \& Bjornstad, O. N. 2004: Spatial synchrony in population dynamics. - Annual Review of Ecology, Evolution and Systematics 35: 467-490.

Mjaaseth, R. R., Hagen, S. B, Yoccoz, N. G. \& Ims, R. A. 2005: Phenology and abundance in relation to climatic variation in a sub-arctic insect herbivore-mountain birch system. - Oecologia 145: 53-65.

Moran, P. A. P. 1953: The statistical analysis of the Canadian lynx cycle. II. Synchronization and meteorology. Australian Journal of Zoology 1: 291-298.

Morris, R. F., Cheshire, W. F., Miller, C. A. \& Mott, D. G. 1958: The numerical response of avian and mammalian predators during a gradation of the spruce budworm. Ecology 39: 487-494.

Myers, J. H. 1988: Can a general hypothesis explain population cycles of forest Lepidoptera? - Advances in Ecological Research 18: 179-242.

Myers, J. H. 1998: Synchrony in outbreaks of forest Lepidoptera: a possible example of the Moran effect. Ecology 79: 1111-1117.

Peltonen, M., Liebhold, A. M., Bjornstad, O. N. \& Williams, D. W. 2002: Spatial synchrony in forest insect outbreaks: roles of regional stochasticity and dispersal. - Ecology 83: 3120-3129.

Raimondo, S., Liebhold, A. M., Strazanac, J. S. \& Butler, L. 2004: Population synchrony within and among Lepidoptera species in relation to weather, phylogeny, and larval phenology. - Ecological Entomology 29: 96-105.

Ranta, E., Lindström, J. \& Lindén, H. 1995b: Synchrony in tetraonid population dynamics. - Journal of Animal Ecology 64: 767-776.

Ranta, E., Kaitala, V., Lindström, J. \& Lindén, H. 1995a: Synchrony in population dynamics. - Proceedings of the Royal Society B 262: 113-118.

Roland, J. \& Embree, D. G. 1995: Biological control of the winter moth. - Annual Review of Entomology 40: 475-492.

Roland, J. \& Myers, J. H. 1987: Improved insect performance from host-plant defoliation: winter moth on oak and apple. - Ecological Entomology 12: 409-414.

Royama, T. 1992: Analytical population dynamics. - Chapman \& Hall, London.

Ruohomäki, K. 1994: Larval parasitism in outbreaking and non-outbreaking populations of Epirrita autumnata (Lepidoptera, Geometridae). - Entomologica Fennica 5: 27-34.

Ruohomäki, K., Tanhuanpää, M., Ayres, M. P., Kaitaniemi, P., Tammaru, T. \& Haukioja, E. 2000: Causes of cyclicity of Epirrita autumnata (Lepidoptera, Geometridae): grandiose theory and tedious practice. - Population Ecology 42: 211-223.

Southwood, T. R. E. \& Comins, H. N. 1976: A synoptic population model. - Journal of Animal Ecology 45: 660-663.

Tanhuanpää, M., Ruohomäki, K. \& Uusipaikka, E. 2001: High larval predation rate in non-outbreaking populations of a geometrid moth. - Ecology 82: 281-289.

Tanhuanpää, M., Ruohomäki, K., Kaitaniemi, P. \& Klemola, T. 1999: Different impact of pupal predation on populations of Epirrita autumnata (Lepidoptera; Geometridae) within and outside the outbreak range. - Journal of 
Animal Ecology 68: 562-570.

Tammaru, T., Kaitaniemi, P. \& Ruohomäki, K. 1996a: Realized fecundity in Epirrita autumnata (Lepidoptera: Geometridae): relation to body size and consequences to population dynamics. - Oikos 77: 407-416.

Tammaru, T., Ruohomäki, K. \& Saikkonen, K. 1996b: Components of male fitness in relation to body size in Epirrita autumnata (Lepidoptera, Geometridae). - Ecological Entomology 21: 185-192.

Teder, T. \& Tammaru, T. 2003: Short-term indirect interactions between two moth (Lepidoptera: Noctuidae) species mediated by shared parasitoids: The benefit of being scarce. - European Journal of Entomology 100: 323-328.

Tenow, O. 1972. The outbreaks of Oporinia autumnata Bkh. and Operophthera spp. (Lep., Geometridae) in the Scandinavian mountain chain and northern Finland 1862-1968. - Zoologiska Bidrag från Uppsala Supplement 2: 1-107.

Tenow, O., Nilssen, E. C., Bylund, H. \& Hogstad, O. 2007: Waves and synchrony in Epirrita autumnatal Operophtera brumata outbreaks. I. Lagged synchrony: regionally, locally and among species. - Journal of Animal Ecology 76: 258-268.

Turchin, P. 2003: Complex population dynamics: a theoretical/ empirical synthesis. - Princeton University Press, USA.

Vinson, S. B. 1976: Host selection by insect parasitoids. Annual Review of Entomology 21: 109-133.

Williams, D. W. \& Liebhold, A. M. 1995: Influence of weather on the synchrony of gypsy moth (Lepidoptera: Lymantriidae) outbreaks in New England. - Environmental Entomology 24: 987-995. 